\title{
RESONANCIAS ACADÉMICAS DEL EQUIPAJE QUE TRAJO AUGUSTO PI SUÑER A VENEZUELA (1939-1962)
}

\author{
Juan José Martín Frechilla
}

Universidad Central de Venezuela

\section{RESUMEN}

Se recorre aquí la sintonía intelectual entre dos fisiólogos: el catalán Augusto Pi Suñer exiliado en Venezuela en 1939 y el venezolano Francisco De Venanzi, más allá de su común campo de investigación, en asuntos como: la inserción académica de las ciencias biológicas y el debate en relación a las ciencias naturales; el fomento de la investigación y la necesidad de captar recursos humanos para su desarrollo; la divulgación de los resultados de los proyectos por medio de órganos institucionales propios; el establecimiento de un cuerpo de legalidad al más alto nivel ejecutivo para el desarrollo de la investigación. Todo ello en el momento en que se formalizan en Venezuela las primeras iniciativas organizativas de su comunidad científica.

KEY WORDS: Política y fomento científico. Investigación universitaria. Médicos españoles exiliados. Universidad Central de Venezuela. Ciencias biológicas.

\section{ACADEMIC RESONANCES OF THE INTELECTUAL BAGGAGE BROUGHT BY AUGUSTO PI SUNER TO VENEZUELA (1939-1962)}

\begin{abstract}
The article read over the intellectual connection between two physiologists, the Catalan exiled Augusto Pi Suñer in 1939 and the Venezuelan Francisco De Venanzi beyond their common research subject like as: the Academic insertion of the Biological sciences and the related debate with the Natural sciences; the Scientific development and the necessity to attract the Human resources for it; the publication of the Project results by owner institutional reviews; the Legal establishment at the highest Govern level to development the Scientific research. All of these subjects were developed when the scientific community in Venezuela are confirming her institutional organization.
\end{abstract}

PALABRAS CLAVE: Politics of scientific development. Academic research. Spanish medical exiled. Universidad Central de Venezuela. Biological sciences. 
1936 fue un año que marcó por razones distintas las historias de España y Venezuela. Aunque con rumbos diferentes, el cruce forjó un territorio común. España iniciaba a longa noite de pedra del franquismo - según la expresiva y terrible síntesis del poeta gallego- y Venezuela comenzaba a deshacer las trazas del gomecismo. Mientras la Segunda República Española enfrentaba un golpe de estado contra su gobierno legal y democráticamente elegido, el nuevo gobierno venezolano, constituido a la muerte natural de Juan Vicente Gómez luego de 27 años de dictadura, abría las posibilidades a una transición hacia la democracia. Ambas circunstancias dieron pie a que nuestro país recibiese de España, en poco más veinte años, un flujo migratorio que creció sin solución de continuidad desde el modesto contingente inicial de exiliados de la Guerra Civil - si se compara con México y Argentina-, hasta el primer lugar de destino de la emigración española a América Latina al final de la década de los años cincuenta $^{1}$. Las coyunturas políticas y sociales de nuestro país ayudan a explicar el desarrollo de este proceso: 1936-1945, transición democrática con gobiernos de elección parlamentaria indirecta; 1945-1948, gobierno, cívicomilitar primero y luego constitucionalmente electo, de impronta socialdemócrata, que reconoció en 1946 al de la Segunda República española en el exilio; 1948-1958, nuevo golpe de estado con gobierno militar, primero colegiado y luego unipersonal; 1958 en adelante, gobiernos electos democráticamente.

\section{CONTEXTO}

Entre 1936 y 1952, la composición profesional de la inmigración selectiva a Venezuela estuvo marcada por las necesidades del relanzamiento del proyecto nacional de modernización emprendido por el Estado, tanto en la administración pública como en la universidad; proyecto que comenzaría a formalizar en la educación y la ciencia las instituciones para su desarrollo ${ }^{2}$. Este

1 En 1957 Venezuela desplazó a Argentina como primer destino con un 52\% del total de la inmigración española a Amética Latina. Las cifras sobre el exilio republicano a Venezuela son precarias y desiguales; una valoración crítica de las cifras se ofrece en MARTín FRECHILLA, J.J. (2005), Nueva Tierra de Gracia: los exilios de la Guerra Civil española en Venezuela 19361951. En Plá Brugat, D. (coord.) (2007), Pan, trabajo y hogar. El exilio republicano español en América Latina, México, SEGOB-Instituto de Migraciones-Centro de Estudios Migratorios/Instituo Nacional de Antropología e Historia/DEG Ediciones SA de CV, pp. 335-458.

2 Martín Frechilla, J.J. (2006), Forja y crisol. La Universidad Central, Venezuela y los exiliados de la Guerra Civil española: 1936-1958, Caracas, Consejo de Desarrollo Científico y Humanístico-UCV. 
relanzamiento, que no se vio mayormente afectado por las coyunturas políticas enumeradas, empujó también una fuerte reactivación del sector privado - en construcción, industria y comercio - gracias a la permeable e incontenible presencia de los ingresos fiscales petroleros. Así, arquitectos 3 y constructores ${ }^{4}$, profesores y maestros ${ }^{5}$, pero sobre todo médicos ${ }^{6}$, se insertaron con fluidez en la sociedad venezolana.

A la muerte de Gómez el 18 diciembre de 1935, el médico Enrique Tejera (1899-1980) fue designado Ministro de Salubridad y de Agricultura y Cría. En poco más de quince días puso en funcionamiento la estructura organizativa de la salud pública al crear un Ministerio de Sanidad y Asistencia Social (MSAS) separado de la cuestión agropecuaria. La iniciativa, que había sido madurada desde la época en la que estuvo a cargo del Laboratorio de Microbiología de la Oficina de Sanidad Nacional en la década anterior $^{7}$, tuvo como objetivo la puesta en marcha de un sistema nacional de salud pública. Éste sería concebido bajo el modelo administrativo de unidades sanitarias y de nuevas unidades técnicas de investigación y control, como lo propugnaba exitosamente en el ámbito internacional la Fundación Rockefeller. Modelo que incorporaba también las discusiones, estructuras y recomendaciones desarrolladas dentro de la Comisión de Malaria de la Liga de las Naciones desde 1924. Los contactos para la cooperación de la Fundación Rockefeller, que habían sido suspendidos en 1933, fueron reanudados por Tejera al llegar al ministerio.

3 El arquitecto sanitario Fernando Salvador, último representante diplomático de la Segunda República española, atrajo a los colegas de su generación: MARTín FRECHILLA, J.J. (1998a), Los olvidados. Fernando Salvador y la arquitectura sanitaria en Venezuela, Tecnología y Construcción, 14 (1), pp. 21-34; MARTín FrECHILLA, J.J. (2001), De diplomático republicano a arquitecto exiliado. Fernando Salvador en Venezuela, Cuadernos Republicanos, 44, pp. 79-97.

4 Martín Frechilla, J.J. (1993), Rafael Bergamín. Tiempos modernos en Caracas. Inmuebles, año 1, 12, pp. 112-114; MARTín FrECHILLA, J.J. (1998b), Sin solución de continuidad. Exiliados e inmigrantes españoles en la construcción de Caracas, 1936-1958, Exils et migrations iberiques au XX $X^{\text {ème }}$ siècle, 5, pp. 207-248.

5 Marques Sureda, S. y Martín Frechilla, J.J. (2002), La labor educativa de los exiliados españoles en Venezuela, Caracas, Fondo Editorial de Humanidades y Educación FHE- UCV.

6 Martín Frechilla, J.J. (2002), El difícil camino de la salud pública. Los médicos españoles exiliados en Venezuela, 1936-1950, Montalban, 36, pp. 221-250; MARTín FreCHILLA, J.J. (2008), El dispositivo venezolano de sanidad y la incorporación de los médicos exiliados de la Guerra Civil española, História, Ciências, Saúde-MANGUINHOS, 15 (2), pp. 519-541.

7 En 1926 Tejera creó la cátedra de Patología Tropical. 
Pero un desencuentro con el Congreso Nacional, en relación a un proyecto de Ley de Defensa Contra el Paludismo, ocasionó la temprana renuncia de Tejera en apoyo a la oposición de los médicos higienistas venezolanos «no satisfechos del plan defensivo» que establecía la ley aprobada. Lo esencial de la controversia era que la ley no reconocía la necesidad de investigar sobre la enfermedad en Venezuela para enfrentar el control o la erradicación del paludismo. Al renunciar, Tejera fue nombrado representante diplomático en Europa, en donde permaneció hasta 1939 al ser designado Ministro de Educación Nacional (MEN). Sin embargo, en positiva connivencia con el nuevo ministro del MSAS, auspició los contratos de los médicos requeridos para el dispositivo de salud pública en progreso. Tejera, que consideraba insuficiente la investigación médica en el país, utilizó su pasantía diplomática para desplegar otras iniciativas con el objetivo de sacar a la universidad venezolana del largo letargo en el cual había estado sumergida durante la dictadura gomecista, en particular con el cierre de la Universidad Central de Venezuela (UCV) por doce años desde 1912. De modo que se impulsó una inmigración selectiva —en algunos casos de alto nivel-en el campo de la medicina, tanto para la universidad como para el MSAS; política que Tejera continuó desde 1939 de nuevo en el gabinete ejecutivo. La concertación entre los dos ministerios — sanidad y educación — permite explicar que se incluyera en los contratos de los médicos exiliados, como parte de su dedicación, la docencia universitaria en cátedras de pre y postgrado, en los casos de quienes habían sido catedráticos y poseían una formación especializada.

En ese marco se sitúa el contrato que firmó Augusto Pi Suñer (1879$1965)^{8}$ con el Ministerio de Educación Nacional en junio de 19399; en él se indicaba que sus servicios «consistirán en investigaciones experimentales de Fisiología Patológica (Cátedra libre de Fisiopatología) y organización del Instituto de Medicina Experimental» ${ }^{10}$. La obra desplegada en Barcelona co-

8 Entre August Pi i Sunyer, Augusto Pi Sunyer y Augusto Pi Suñer, se ha optado por la castellanización, en razón a que es la utilizada por el propio Pi Suñer en los documentos firmados durante su exilio venezolano; cuando incluimos alguna cita textual respetamos el nombre y los apellidos en catalán cuando sea el caso.

9 La inmigración selectiva tuvo dos vertientes fundamentales: quienes tenían experiencia y una carrera desarrollada en sus países de origen: Santiago Ruesta (1899-1960), José Sánchez Covisa (1881-1944) y Augusto Pi Suñer en España o Martín Meyer (1975-1951) en Alemania; y quienes habían obtenido recientemente un doctorado de interés, como fue el caso de Werner G. Jaffe y Herman Kaiser nacidos en la primera década del siglo XX y doctorados en Química en Suiza y Alemania en la del treinta.

10 Archivo del Consejo Universitario de la Universidad Central de Venezuela (ACUUCV), CU 2, 1939. En 1942, el Ministerio de Educación Nacional amplió la contratación de Pi Suñer 
mo director del Instituto de Fisiología ${ }^{11}$ fue el aval que llevó a Enrique Tejera a valorar lo pertinente de la contratación de Pi Suñer para situarla en el objetivo de la formación de investigadores y el desarrollo de la infraestructura académica y administrativa adecuada para ello. En la Facultad de Ciencias Médicas de la UCV lo esperaban quienes se reconocerían después como sus discípulos: Humberto García Arocha (1912-1995), Jefe de los Trabajos Prácticos, y Marcel Granier-Doyeux (1916-1996), Preparador ${ }^{12}$. Un año después, a mediados de 1940, Francisco De Venanzi (1917-1987) fue designado Preparador por Concurso en la Cátedra de Fisiología - en ese momento detentada por Pi Suñer-, hasta que obtuvo en 1942 el título de Doctor en Ciencias Médicas. El fisiólogo catalán encontró, en el todavía en ciernes venezolano, la sintonía científica y el talante liberal necesarios para que sus ideas sobre la investigación, su fomento y desarrollo, resonaran positivamente y fueran con el tiempo potenciadas y ampliadas por De Venanzi. Los recorridos de sus carreras - una por terminar y otra por comenzar - dan cuenta, más allá del encuentro que la fisiología les pudo brindar como docentes e investigadores, que entre ambos es posible establecer una clara concertación de intereses en la perspectiva de determinadas coyunturas e iniciativas universitarias. Asuntos como: la inserción académica de las ciencias biológicas y el debate en relación a las ciencias naturales; el fomento de la investigación universitaria y la necesidad de captar recursos humanos para su desarrollo; la divulgación de los resultados de los proyectos por medio de órganos institucionales propios; o la necesidad de establecer un cuerpo de legalidad al más alto nivel ejecutivo para el desarrollo de la investigación en el país, son algunos de los asuntos que vamos a detallar para mostrar la conexión - y las resonancias- entre Augusto Pi Suñer y Francisco De Venanzi ${ }^{13}$.

con los cursos de Biología y Bioquímica del Instituto Pedagógico Nacional; en 1944, la Facultad de Medicina Veterinaria de la UCV, por intermedio del Ministerio de Agricultura y Cría, lo contrató para la Cátedra de Bioquímica. Hasta 1946, cuando se aprobó el Estatuto Orgánico de la Universidades Nacionales, la universidad no podía contratar directamente a profesores e investigadores.

11 Centro de investigación experimental fundado en 1920 por la entonces denominada Mancomunitat de Catalunya (1914-1925) a iniciativa de Augusto Pi Suñer. Grases, P. y Molas, P. (dir.) (1988), 200 Catalans a les Amèriques 1493-1987, Barcelona, Comissió Catalana del Cinquuè Centenari del Descobriment d'Amèrica, pp. 490-493.

12 Granier-DoyeuX, M. (1962), La obra de Pi Suñer en Venezuela, Acta Cientifica Venezolana, 13 (5), pp. 164-168.

13 Otra historia de equipaje y resonancias es la que sintoniza a Martin Mayer (1875-1951) con Felix Pifano (1912-2003); Mayer, doctorado en medicina en Heidelberg en 1900, luego de 
En otra dimensión del compromiso universitario, se podría finalmente agregar que ambos asumieron en su momento, mas allá de la fisiología y del ideario en torno a la investigación y su desarrollo, la conducción política de la vida académica con talante liberal y democrático. Así como Augusto Pi Suñer fue miembro del Patronato de Gobierno de la Universidad Autónoma de Barcelona (1933-1939) ${ }^{14}$, Augusto De Venanzi fue el primer Rector de la Universidad Central de Venezuela (1959-1963), electo por un claustro, a su vez electo, compuesto por profesores y una representación proporcional de estudiantes; y ello, de acuerdo a las pautas autonómicas recogidas en la Ley de Universidades aprobada en 1958.

\section{EQUIPAJE}

\section{Autonomía y extensión}

El contacto de Augusto Pi Suñer con profesores y estudiantes de una universidad latinoamericana sobre temas no directamente científicos se produjo en 1919 en la Universidad de Córdoba, a un año del llamado de «La Juventud Argentina de Córdoba a los Hombres Libres de Sud América». En unas breves palabras de salutación — previas a una de las conferencias públicas del programa científico de su viaje ${ }^{15}$ - , expuso cómo la renovación académica latinoamericana había también aireado a la universidad española:

«creo que esta influencia va aún más lejos todavía, influyendo también directamente sobre la universidad española, la universidad clásica, vieja, hoy adormeci-

haber trabajado entre 1904 y 1935 en el Instituto de Enfermedades Tropicales de Hamburgo, llegó a Venezuela en 1939, contratado por el Instituto Nacional de Higiene (INH) del Ministerio de Sanidad y Asistencia Social, y para revitalizar en la UCV la cátedra de Patología Tropical en la cual se encontraba Pifano, graduado de Doctor en Ciencias Médicas en 1935 tutelado por Enrique Tejera quien, recordemos, había sido el fundador en 1926 de esa cátedra. Mayer y Pifano crearon en 1940 la Sección de Investigaciones Patológicas del INH hasta que finalmente, en 1947, Pifano logró - no sin dificultad- que se crease en la UCV el Instituto de Medicina Tropical.

14 Grases, P. (1997), Augusto Pi Sunyer. En Diccionario de Historia de Venezuela, Caracas, Fundación Polar, t. 3, p. 625

15 Para esta sección, además de las referencias a fuentes publicadas, vamos a utilizar las documentales del Archivo de la Junta para Ampliación de Estudios, Residencia de Estudiantes, Madrid (AJAE) recogidas en dos legajos: Augusto Pi Suñer, exp. 115-404 y Congreso de Fisiología, exp. 155-71. 
da, que exige nuevas formas, la llegada de vientos de afuera, la revolución universitaria que le infiltre la necesaria modernidad (...) vuestros problemas universitarios son asimismo los nuestros ${ }^{16}$ ».

Pi Suñer recordaba el decreto de autonomía logrado ese mismo año en España, gracias a la presión ejercida en los congresos universitarios; recordaba especialmente cuando en el de Barcelona de 1918 — que él presidió-, estudiantes y profesores redactaron «un proyecto de estatuto de la universidad catalana autónoma», para agregar: «conocedores nosotros de la renovación que en las universidades de la república Argentina se operaba, tuvimos muy en cuenta las disposiciones de vuestra Reforma de 1918». La declaración remitía al posicionamiento intelectual con el que España se estaba aproximando, luego de la crisis que supuso la tardía independencia de Cuba, a unas relaciones en pie de igualdad con las repúblicas americanas. Era una adecuada asunción de la huella que había dejado, entre la comunidad científica española y quienes componían la Junta para la Ampliación de Estudios e Investigaciones científicas (JAE), el informe En América, una campaña de Adolfo Posada (1860-1944) ${ }^{17}$, luego del viaje de 1911 a Argentina. El informe proponía «establecer con Hispanoamérica una cooperación intelectual sólida que tuviese como base la cultura común, y que abandonase los proyectos paternalistas de acudir en ayuda de América» ${ }^{18}$. Pi Suñer se encontraba en 1919 en Argentina para dictar en la Universidad de Buenos Aires un curso, auspiciado por la Institución Cultural Española de esa ciudad, titulado Los mecanismos

16 Pi SuÑER, A. (1919), Influencia del Movimiento Argentino en las Universidades Españolas. En VV.AA. (1978), La Reforma universitaria (1918-1930), Caracas, Biblioteca Ayacucho, pp. 155-156.

17 Discípulo de Francisco Giner de Los Ríos, era en esos años catedrático de Derecho Político en la Universidad de Oviedo, luego, desde 1919 lo sería de la de Madrid. Adolfo Posada había publicado, entre 1906 y 1909 varios artículos en El Diario Español de Buenos Aires, totalmente alejados de la reconquista espiritual de la hispanización y de la pretensión de ejercer influencia alguna sobre el destino de los países latinoamericanos. El viaje estuvo auspiciado por la JAE. GARCÍA, I. (2000), El institucionismo en los krausistas argentinos. En Biagini, H.E. (comp.), Arturo Ardao y Arturo Andrés Roig. Filósofos de la autenticidad: Jornada en homenaje a Arturo Andrés Roig y Arturo Ardao, patrocinada por el Corredor de las Ideas y celebrada en Buenos Aires, el 15 de junio de 2000, edición digital accesibel en http://www. ensayistas.org/filosofos/argentina/roig/homenaje/garcia.htm (consultado el 08-04-2010).

18 Citado en LóPez SÁnCHEZ, J.M. (2007), La Junta para Ampliación de Estudios y su proyección americanista: La institución Cultural Española en Buenos Aires, Revista de Indias, LXVII (239), pp. 81-102, p. 87. 
de correlación fisiológica, adaptación interna y unificación de funciones ${ }^{19}$. Pero sin duda, en la intervención de la Universidad de Córdoba hablaba el científico prestado a la política, quien entonces era Diputado a las Cortes por Figueras (Girona) ${ }^{20}$ y al inaugurarse como tal había dicho, en abril de 1918: «pedimos la autonomía universitaria porque queremos la universidad dueña de sus propios destinos, ni sometida al gobierno del estado, ni sometida tampoco a las corporaciones locales» ${ }^{21}$.

En los países europeos las relaciones culturales habían comenzado a ser, desde finales del siglo XIX, un componente de las exteriores. En España, establecer un tejido con América Latina debía enfrentar - y romper - lo que en acertada síntesis Leopoldo Zea denominó el proceso de «desespañolización» posterior a la independencia; los intentos por establecer algún tipo de relación o intercambio habían sido, la mayoría de las veces, infructuosos ${ }^{22}$. El más difundido ocurrió en 1904 cuando la Unión Ibero-Americana ${ }^{23}$ de Madrid concibió, con apoyo oficial, la creación — anexa a la Universidad de Salamanca - de una Universidad Hispanoamericana para que los estudiantes latinoamericanos fuesen a estudiar a España en vez de ir a las universidades francesas, inglesas o alemanas. El proyecto no pasó del papel a pesar del apoyo de una parte de la comunidad española de Argentina, - la más cercana ideológica y políticamente a la Unión Ibero-Americana - que llegó a enviar a España a un portavoz en un recorrido de propaganda que incluyó conferencias

19 En 1920 la Editorial Minerva de Barcelona publicó un libro con ese mismo título en el que se recogen los textos de las clases dictadas, en agosto de 1919, en la Facultad de Ciencias Medicas de la Universidad de Buenos Aires. VALENTI CAMP, S. (1922), Ideólogos, teorizantes $y$ videntes, Barcelona, Editorial Minerva, pp. 433-436, disponible en http://www.filosofía.org (consultado el 08.04.2010).

20 Augusto Pi Suñer fue electo diputado en las elecciones de 24 de febrero de 1918, luego lo seria en las de 1 de junio de 1919 y, finalmente, el 19 de diciembre de 1920.

21 Pereira, J. (2004), Dr. Augusto Pi Suñer: Maestro Revolucionario, Vitae (revista digital del Instituto de Medicina Tropical, Universidad Central de Venezuela), 20, disponible en: http://vitae.ucv.ve/?module=articulo\&rv $=68 \& \mathrm{n}=2531$ (consultado el 08.04.2010).

22 Escapa a nuestras posibilidades - y al interés de este artículo- la revisión de la abundante literatura que sobre éste periodo de la historia española, en especial la de sus relaciones con América Latina, se ha publicado a ambos lados del Atlántico; los casos seleccionados y los personajes involucrados - Asociación Española para el Progreso de las Ciencias, Institución Cultural Española, José Rodríguez Carracido, Rafael Altamira... - tienen en la mira llenar el equipaje de Pi Suñer de aspectos singulares que resonarán en su exilio venezolano.

23 Para dibujar su plataforma ideológica, basta recordar que a ella se debe la exitosa iniciativa de instaurar en 1913 la «Fiesta de la Raza», luego desde 1915 «Día de la Raza» hasta que en los años cincuenta el gobierno franquista lo rebautizo como «Día de la Hispanidad». 
y una visita al Rey ${ }^{24}$. Entre quienes se opusieron en España al proyecto estuvo Rafael Altamira (1866-1951), catedrático de derecho —al igual que Posadas - en la Universidad de Oviedo ${ }^{25}$. Altamira fue el creador de una unidad de Extensión Universitaria, con el objetivo de difundir, por medio de actividades de divulgación al público en general, los conocimientos que generaba su universidad ${ }^{26}$. Este modelo implantado en las universidades europeas se extendió después por América Latina; en Venezuela lo haría en la década de los años cuarenta.

Pero un proyecto que si prosperó aunque sobre bases distintas fue la creación luego del viaje de Posada, de la Institución Cultural Española (ICE) de Buenos Aires en 1914. Para ese momento en España se habían «puesto en marcha una serie de iniciativas de clara raíz institucionalista por parte de algunos gabinetes liberales» ${ }^{27}$ que culminaron con la creación, en 1907, de la Junta para la Ampliación de Estudios e Investigaciones Científicas (JAE), cuando el médico Amalio Gimeno (1852-1936) era Ministro de Instrucción Pública y Bellas Artes. Pero sería a partir de 1910, con los liberales de nuevo en el gobierno, cuando la relativa autonomía de la JAE estuvo en capacidad de poner en marcha un dispositivo institucional completo para la modernización de la ciencia española. La Institución Cultural Española, con los aportes económicos de sus socios, y una junta directiva a la cual fueron integrados los organismos más representativos de la colonia española ${ }^{28}$, creó una cátedra en la Universidad de Buenos Aires para conocer y difundir «las investigaciones y estudios científicos y literarios que se realicen en España». La figura clave del proyecto fue Avelino Gutiérrez (1864-1945), nacido en Santander pero graduado de médico cirujano en Argentina en 1890; Gutiérrez, quien era en-

24 GARCía (2000), p. 7.

$25 \mathrm{Si}$ bien algunos autores españoles sugieren que Altamira estaba a favor del proyecto, nos adherimos al documentado análisis que elabora Ignacio García en el texto citado. Altamira realizó durante nueve meses, entre 1909 y 1910, un viaje de estudios por Buenos Aires, Montevideo, Santiago, Lima, México y, finalmente La Habana, con cuya universidad, la de Oviedo tenia especial interés por establecer un intercambio. Altamira publicó en 1911 Mi viaje a América.

26 Moreno SÁEz, F. (2005), Rafael Altamira y la Extensión Universitaria, Alicante, Biblioteca Virtual Miguel de Cervantes, disponible en http://www.cervantesvirtual.com/FichaObra. html?Ref=14882 (consultado el 08.04.2010).

27 LÓPEZ SÁNCHEZ (2007), p. 82.

28 Los presidentes de: el Club Español, la Asociación Patriótica Española — creada para apoyar la causa española cuando la guerra de Cuba-, la Cámara Española de Comercio, la Asociación Española de Socorros Mutuos, la Sociedad Española de Beneficencia. LóPEZ SÁNCHEZ (2007), p. 89. 
tonces director del Hospital Español, sería por más de una década el presidente de la ICE e impulsor del modelo en centros similares en Montevideo y Santiago de Chile.

En diciembre de 1917 Avelino Gutiérrez le escribía al Presidente de la JAE, Santiago Ramón y Cajal, solicitando que se realizasen con tiempo las gestiones para la venida en 1918 del profesor que fuese designado; al respecto - «sin que ello signifique excluir la absoluta facultad de esa Junta para proponer nombres de personas de otra especialidad»—Gutiérrez indicaba:

«Esta Institución vería con agrado que el profesor a designarse explicara materias técnicas en ciencias médicas, naturales o físicas, a fin de que nuestros cursos tuvieran así la mayor variedad posible y pudiera satisfacerse el deseo de que en todas las Facultades que componen esta Universidad realice su obra, en sucesiva rotación, la Cultura Española. Como es sabido, a la Facultad de Filosofía y Letras correspondió por dos períodos con las conferencias de los Sres. Menéndez Pidal y Ortega y Gasset; y el último curso, con el Sr. Rey Pastor, a la Facultad de Ciencias Exactas, Físicas y Naturales ${ }^{29} \gg$.

Semanas antes la JAE, por medio de su secretario José Castillejo, ya le había solicitado a Augusto Pi Suñer los recaudos para su postulación, así como su consentimiento para hacerla. La carta de Gutiérrez se cruzó con la de Ramón y Cajal en la cual proponía a Pi Suñer con fechas, titulo del curso y número de lecciones: «el curso sería de naturaleza experimental, fundado en investigaciones propias y dando información sobre trabajos ajenos», al cual se sumaria un grupo de "conferencias públicas de vulgarización científica»a modo de extensión universitaria ${ }^{30}$. Pi Suñer cumplía con el perfil del candidato solicitado. Ramón y Cajal escribió: tiene «firme prestigio entre el profesorado español»; formado «al lado de su padre, de Turró y de Carracido, ha hecho frecuentes viajes al extranjero y ha frecuentado Congresos Internacionales»; colabora en revistas francesas y alemanas; y, «actualmente, a más de la cátedra en la Universidad, dirige trabajos en la Sociedad de Biología de Barcelona y en el Instituto de Estudios Catalanes» ${ }^{31}$.

29 AJAE exp. 115-404, fols. 9a y 9b. 13 de diciembre de 1917.

30 Una de las conferencias que Pi Suñer preparó para su viaje a Argentina, La guerra y el hambre de los pueblos, fue dictada posteriormente bajo el titulo El hambre de los pueblos como discurso inaugural en la Academia de Medicina de Barcelona en 1922. El apunte, como veremos, guarda relación con el campo de la nutrición y el particular interés de Francisco De Venanzi por desarrollar, como así fue, una línea de investigación al respecto.

31 AJAE exp. 115-404, fols. 10a a 10c, 21 de diciembre de 1917. 


\section{Política y fomento}

En la carta aceptando la postulación, Pi Suñer le escribió a Castillejo ${ }^{32}$ : «Al terminar mi carrera vine a Madrid. El estudio de la química biológica con $\mathrm{Ca}$ rracido acabó de terminar mis aficiones». Pero la influencia del químico y farmacólogo José Rodríguez Carracido (1856-1928) fue no solo significativa en el moldeado de sus intereses hacia la investigación científica sino que se encadenó hacia la docencia universitaria que posteriormente desarrollaría en esas áreas. Por otra parte, cuando el 2 de enero de 1908 fue convocada en Madrid la reunión constitutiva de la Asociación Española para el Progreso de las Ciencias (AEPC), Carracido, miembro del grupo inicial, fue designado para elaborar los estatutos de la nueva institución. En los congresos de la AEPC —el primero se celebró ese mismo año en Zaragoza - comenzaron a reunirse investigadores de las distintas disciplinas científicas, tanto los de reconocida trayectoria como los jóvenes, para presentar los avances de sus trabajos ${ }^{33}$. Tuvo entonces Pi Suñer de primera mano - dados sus vínculos con Carracido- el significado y los objetivos de esta asociación, a cuyas reuniones asistiría con regularidad.

En la carta Pi Suñer detallaba: sus trabajos y las referencias que a ellos habían hecho investigadores extranjeros; las asistencias a los congresos internacionales de fisiología como la forma de «enterarme y ponerme en relación con los hombres mas representativos, y adquirir el material de laboratorio y bibliográfico necesario» a fin de establecer el «intercambio espiritual con los distintos centros europeos y americanos y nuestro pequeño grupo»; las responsabilidades como redactor de tres revistas internacionales; la fundación de la Societat de Biología auspiciada por el Institut d'Estudis Catalans y la publicación de su revista. Escribía también sobre las dificultades: «No pude marchar al extranjero» a especializarme ya que «no existía entonces la Junta» ${ }^{34}$; sobre los contratiempos en las oposiciones y la necesidad de ejercer

32 AJAE exp. 115-404, fols. 8a a 8f, 26 de noviembre de 1907.

33 García Sierra, P. (1993), La evolución filosófica e ideológica de la Asociación Española para el Progreso de las Ciencias (1908-1979), El Basilisco, $2^{\circ}$ época, 15, pp. 49-81,

34 En 1907, Pi Suñer solicitó su designación, como representante oficial al Congreso de Fisiología, celebrado en Heildelberg, al Ministerio de Instrucción Pública y Bellas Artes; para ese momento Amalio Jimeno — creador de la JAE — había dejado el ministerio y el nuevo ministro era Faustino Rodríguez San Pedro, el que desde la Unión Ibero-Americana propondría pocos años después la «Fiesta de la Raza»; la solicitud fue remitida a la JAE cuando ya Pi Suñer había asistido como particular al congreso. A partir de ese primer intento Pi Suñer solicitaría regularmente a la JAE su designación y la subvención para asistir — como así fue- a los congresos de Viena, Groningen, Paris .... AJAE exp. 115-404, fols. 1a a 1d, 5a a 5b, 6, 69 
como médico: «fui derrotado (...) en mis primeras oposiciones a la cátedra de Sevilla», aunque dos años después lo lograse, sin embargo, agregaba: «mi historia de Sevilla V. la sabe ${ }^{[35]}$. Me encontré sin laboratorio, sin probabilidades de conseguirlo y en cambio en Barcelona iba, con penas y trabajos, constituyendo un núcleo de material y aun de gente con quien poder contar». Con respecto al tiempo requerido para dedicarse a la investigación escribía:

«He tenido que dedicarme al ejercicio de la profesión, y esta es mi tragedia. Pero procuro recortar a este ejercicio cuantas horas puedo. Antes de mi reingreso en el Profesorado, todas estas horas robadas a la medicina eran destinadas a la investigación. Ahora he de repartirlas entre la investigación y la cátedra. Pero resuelvo en parte el conflicto, que es muy grave, haciendo que los alumnos mas dignos de atención se interesen en mis cosas».

Lista de carencias y necesidades: subvenciones para ventilar entre los pares los resultados de las investigaciones; visibilidad de los trabajos en revistas especializadas de reconocido prestigio; dotación de materiales, equipos y bibliografía al día; tiempo integral dedicado a la investigación. Una lista con la cual nos toparemos también al otro lado del Atlántico.

Cuando la cátedra del ICE — «bajo el patrocinio científico y moral» de la Junta para la Ampliación de Estudios e Investigaciones Científicas- le fue finalmente encomendada en marzo de 1918 a Pi Suñer, surgieron los primeros inconvenientes para cuadrar las fechas y el tiempo de la estadía. Adujo en primer lugar que no podían ser cinco meses sino a lo sumo tres; después puso reparos a los meses propuestos. Finalmente expuso razones personales -el inesperado embarazo de su esposa - para solicitar, primero, que el viaje se desplazase a finales de 1918, y luego que fuese diferido a junio de 1919, ya que para entonces, decía: «mis trabajos que van bien, estarán maduros en su punto». Lo que si negó de plano es que el ajuste propuesto estuviese vinculado a su elección como diputado a las Cortes el 24 de febrero de 1918: «No piense ni por un momento que esta accidental campaña política me distraiga de mis aficiones. No he sabido negarme por la distinción de que me hacían objeto y también por explorar otro mundo» ${ }^{36}$. El contratiempo supuso para la

35 Se refiere a su solicitud ante la Junta de Pensiones para seguir, «durante el curso 1907 a 1908, en los laboratorios de Fisiología de la Facultad de Medicina y Microbiología municipal de Barcelona», los trabajos, "acerca de las funciones renal y hepática», que no puede adelantar en Sevilla por carecer allí de un laboratorio adecuado. AJAE exp. 115-404, fols. 2a a 2b.

36 Ya en 1910, Pi Suñer le informaba a Castillejo que le estaban insistiendo para que acompañase a Luís Zulueta, (1878-1964), pedagogo catalán de origen vasco y profesor del Instituto Libre 
JAE una trabajosa negociación con el ICE por el poco tiempo que había para definir a un substituto ${ }^{37}$; pero lo que inclinó la balanza para diferir por un año el viaje de Pi Suñer, fue el visto bueno de Avelino Gutiérrez, quien sin duda prefirió un médico del perfil del fisiólogo catalán y así lo hizo saber.

Sin embargo, hubo también otra circunstancia que jugó a favor de Pi Suñer para diferir el viaje y mantener la candidatura: había sido designado como Vocal de la Junta Plena de la JAE ${ }^{38}$. Todo se aclara en 1923, cuando Pi Suñer que ya no era diputado a las Cortes le escribió a Castillejo: «al proponerme V. la aceptación de un cargo en la Junta - cosa que tanto me honra - me habló de mi representación política (...), bastaría pues una ligera indicación confidencial para presentar la dimisión»; viene a cuento la cita de Antístenes «No hay que estar tan cerca del poder que nos queme, ni tan lejos que nos hiele». Castillejo le responde que consultará «la duda de usted, llena de delicadeza y de objetividad, acerca de si debe continuar formando parte de la Junta» ante la nueva situación; pero da su opinión:

«A mi personalmente me parece que lo esencial es la colaboración moral y científica que usted nos prestó lo mismo antes que después de entrar en esta corporación. Su presencia en ella quería añadir a esa colaboración las ventajas de su prestigio ante la opinión y ante los partidos. Es decir, realizaba usted el ideal de un miembro de esta Junta por tener la formación científica y la fuerza de opinión.

En qué medida esta segunda circunstancia halla podido disminuir al dejar usted de ser político, no la puedo graduar sin cambiar impresiones con las gentes que mueven la opinión en Cataluña y fuera de ella.

\footnotetext{
de Enseñanza, como candidato de la izquierda catalana; decía Pi Suñer entonces: «estoy muy lejos de la política y me encontraría en cargo totalmente desconocido». AJAE exp. 155-71.

37 Se habló primero de Ramón Turró (1854-1926) pero el propio Pi Suñer lo desechó porque estaba un tanto retirado; luego, Julio Rey Pastor propuso a Esteban Terradas (18831950) quien le escribió a Castillejo: «no tengo deseo alguno de ir». AJAE exp. 115-404.

38 «El organigrama organizativo de la JAE quedó diseñado en torno a 21 vocales y cuatro cuerpos de administración: la Presidencia (...), la Junta Plena, formada por los 21 vocales y el secretario, la Comisión ejecutiva o directiva, integrada por el presidente, dos vicepresidentes, dos vocales y el secretario (...) y la Secretaría». LÓPEZ SÁNCHEZ (2007), p. 83. Augusto Pi Suñer fue el primer catalán en ser designado vocal de la JAE. Hasta 1918 los datos por comunidades corresponden a $26 \%$ castellanos, $15 \%$ navarros y valencianos, $11 \%$ andaluces, asturianos y gallegos; hasta la misma fecha el perfil disciplinar refleja 54\% Ciencias Sociales y Humanidades y 46\% Ciencias Básicas y Naturales; Pi Suñer tenía, en 1918, 40 años y la edad promedio de sus compañeros de Junta era 52 años. Datos elaborados a partir de una tabla preliminar (nombres y períodos) facilitada por el Centro de Documentación de la Residencia de Estudiantes, Madrid, y una búsqueda realizada por el autor en Google con los nombres de los vocales.
} 
Esté usted seguro de que por mi parte le diré con entera sinceridad si me parece que se ganaría o se perdería en nuestra obra con el alejamiento de la personalidad de usted ${ }^{39} \gg$.

Así como sus pasantías por las Cortes (1918-1923) y por la JAE (19181924) permitieron a Pi Suñer valorar las claves de su ideario científico ${ }^{40}$, el viaje a Argentina en 1919 llenó de contenido su carrera de investigador. La JAE lo felicitó por el éxito «al parecer, no solo científico, sino también político y nacional»; el curso, para el cual trasladó varios equipos —un aparato de circulación artificial entre otros- dadas sus características prácticas, contó además con una pensión adicional para un ayudante. Antes de regresar, la Academia de Medicina lo designó, junto a Santiago Ramón y Cajal, miembro honorario «en homenaje a la ciencia española contemporánea», según lo informó a la JAE Avelino Gutiérrez.

En Argentina conoció a Bernard Houssay (1887-1971) que buscaba consolidar entonces una posición académica en la Universidad de Buenos Aires. Sobre ese encuentro Houssay diría años después: «no olvido la gratitud que le debo, porque sus conferencias en Buenos Aires en 1919, inclinaron a los consejeros de la Facultad de Medicina a designarme profesor y fundar el Instituto de Fisiología como centro de docencia e investigación ${ }^{41}$. En 1920, mientras en Buenos Aires Houssay era nombrado director del nuevo Instituto de Fisiología, Pi Suñer lo era del homónimo catalán. No deja de ser significativa la oportunidad en la cual Houssay expresaba públicamente su gratitud a Pi Suñer, se trataba del discurso inaugural de la IX Convención Anual de la Asociación Venezolana para el Avance de la Ciencia (AsoVAC) celebrada en Caracas en 1958 a la que había sido invitado por Francisco De Venanzi. Houssay, antes del saludo y homenaje a Pi Suñer, había dicho:

«Sin querer inmiscuirme en la política interna, no pude aceptar las amables invitaciones que me fueron formuladas porque no quería visitar la Universidad mientras algunos de sus más eminentes profesores estuvieran desterrados y fueran per-

39 AJAE exp. 115-404, fols. 71a a 71b, 1 de junio de 1923. La carta finaliza informando a Pi Suñer que las 5.000 pesetas del premio de fisiología enviadas por Avelino Gutiérrez que inicialmente había pensado dedicar a su laboratorio ahora se destinaría a pensiones.

40 En la Junta Plena de la JAE, Pi Suñer fue vocal junto a Amalio Gimeno, José Rodríguez Carracido y Rafael Altamira.

41 Houssay, B. (1958), La investigación científica en Latinoamérica, Acta Científica Venezolana, 9 (5), p. 101. 
seguidos. Derrocado el sistema despótico y restablecida la libertad académica, me he apresurado a aceptar esta nueva invitación».

Otro era entonces el momento 42 .

\section{Ciencia e ideología}

Desde el contacto de 1919, los vínculos - directos e indirectos- de la escuela catalana de fisiología con América Latina se mantuvieron. Sobre la trascendencia de este grupo de investigación y su impacto, Francisco Giral escribe a propósito de Venezuela: «es difícil evaluar relativamente qué fue más importante, si la escuela fisiológica catalana o la escuela experimental venezolana». Comparación y equivalencia innecesaria, sobre todo si, para inclinar su punto de vista hacia el tiempo del exilio, el autor eleva a veinticinco los años durante los cuales Pi Suñer dirigió el Instituto de Medicina Experimental en Caracas ${ }^{43}$; fueron once, y muy fructíferos. En mayo de 1950, solicitó la jubilación por razones de salud: «fui afectado — explicaba- por un considerable accidente vascular cerebral» a comienzos de $1949^{44}$. La precisión es necesaria, no tanto porque un texto reputado convierte en hecho lo que no es, sino porque se debe situar el alcance de su actividad científica en el exilio venezolano para contrastar críticamente su labor tanto en el desarrollo de la investigación como en su trabajo de promotor institucional de la actividad científica en Venezuela.

Augusto Pi Suñer se graduó de licenciado en medicina en 1899 y obtuvo el doctorado en Madrid un año después. Sobre su obra científica y sus iniciativas para desarrollarla entre 1904 y 1939 existen diversas apreciaciones de quienes en España han trabajado la historia de la ciencia antes de la Guerra Civil. Josep Lluis Barona sostiene, que además de Madrid:

42 Después de un ensayo de autonomía en 1946 con el Estatuto Orgánico de las Universidades Nacionales, luego del golpe cívico-militar que hizo caer al régimen de Marcos Pérez Jiménez en enero de 1958, Francisco De Venanzi fue designado, primero, presidente de la Comisión Universitaria, luego Rector encargado de la UCV, hasta que a finales de 1958, tal como lo pautaba la nueva ley, fueron convocadas las elecciones universitarias en las cuales fue electo.

43 Giral, F. (1994), Ciencia española en el exilio (1939-1989). El exilio de los científicos españoles, Barcelona, Editorial Anthropos, p. 210.

44 ACUUCV, CU 5, 1950; al solicitar su jubilación Pi Suñer trató de que la UCV contratase para dirigir el IME a Bernard Houssay, el Consejo Universitario designó, al estar Humberto García Arocha en el exilio, a Marcel Granier-Doyuex. 
«la labor de creación de instituciones científicas que realizó la Mancomunitat de Catalunya dio abundantes frutos gracias a una serie de figuras que con su preparación y la calidad de su trabajo contribuyeron a llenar de contenido un proyecto institucional de gran alcance. El Institut d'Estudis Catalans creó desde su origen una sección de ciencias dedicada a la investigación de las ciencias matemáticas, físico-químicas y biológicas»,

sección que contó al inicio con siete miembros: un médico, un matemático, un economista, un zoólogo, un filosofo y dos biólogos: Augusto Pi Suñer y Ramón Turró ${ }^{4}$. Si bien el Instituto, creado en 1907 — continúa Baronahabía tenido como antecedente en el ámbito de las ciencias biológicas y de la medicina, el Laboratori Municipal (1887) y la obra de Ramón Turró a principios de siglo, Pi Suñer «supo crear un núcleo dedicado a la experimentación biológica en torno al Laboratorio y el Instituto de Fisiología que se interesaron sobre todo por aspectos de la fisiología, la bioquímica y la farmacología» ${ }^{46}$. La labor de promoción y divulgación del Instituto se mantuvo hasta el final de la guerra con la publicación de revistas y un amplio programa de premios y bolsas de estudio para el «fomento de la investigación científica en tierras de Cataluña». Entre 1902 y 1904, Pi Suñer ejerció como profesor auxiliar de Fisiología hasta que obtuvo la cátedra en la Universidad de Sevilla, aunque no perdió el vínculo con el Laboratorio Municipal al organizar con Turró cursos permanentes de Fisiología general ${ }^{47}$. A la muerte de Ramón Coll y Pujol (1845-1915), Pi Suñer lo sucede en la cátedra de Fisiología de la Universidad de Barcelona desde 1916. Además de su labor como docente e investigador, promovió en 1912 la fundación Societat Catalana de Biología y dirigió entre 1913 y 1938 su revista Treballs de la Societat Catalana de Biología; a la vez que desde 1911 colaboró activamente en los Arxius del Institut de

45 Barona, J.L. (1995), Ciencia y exilio. La significación histórica del fisiólogo José Puche. En Girona, A. y MAnCEBo, M.F. (eds.) (1995), El exilio valenciano en América. Obra y Memoria, Valencia, Instituto de Cultura Juan Gil-Albert y Universitat de València, pp. 39-52. Mientras Barona los sitúa disciplinarmente como biólogos, Sánchez Ron lo hace como fisiólogo y bacteriólogo respectivamente: SÁNCHEZ Ron, J.M. (1999), Cincel, martillo y piedra. Historia de la ciencia en España (siglos XIX y XX), Madrid, Santillana, p. 231.

46 BARONA (1995), p. 45. Entre los que aquí trabajaron se encontraban Jaume Pi Sunyer, Jesús M. Bellido Golferichs, Rosendo Carrasco Forminguera y José Puche, entre muchos otros. Rosendo Carrasco Forminguera sería llamado por Pi Suñer a Caracas a raíz de su accidente cerebro vascular. ACUUCV, CU 5, 1950

47 SÁnCHEZ Ron (1999), p. 297. Ya hemos relatado en la sección anterior como le fue en Sevilla. 
Ciènces del Institut d'Estudis Catalans ${ }^{48}$; entre 1926 y 1939 presidió la Academia de Medicina de Barcelona. Pero había tiempo para más; si bien en 1910 le escribió - como ya dijimos - a Castillejo, «estoy muy lejos de la política», lo cierto es que ese mismo año aparece entre los fundadores de la Uniò Federal Nacionalista Republicana; y, en 1917, luego de los cruces y reagrupaciones de la singularmente efervescente la vida política catalana de esos años, lo encontramos como miembro de la primera junta directiva del Partit Republicà Català ${ }^{49}$.

Pero la intensa pesadumbre que carga todo exilio hace difícil una valoración desprejuiciada, en este caso de la productividad y el impacto científico de obra americana de Pi Suñer; la que a nosotros nos incumbe. Ernesto García Camarero es, creemos, quien más ayuda ofrece al resaltar las claves de esta dificultad, que se remontan a cuando compiló junto a su hermano, los textos necesarios para analizar la denominada «polémica de la ciencia española» ${ }^{50}$. Con el fin de situar el contenido de la transferencia, en La ciencia española en el exilio ${ }^{51}$ señala:

«la ciencia no ha arraigado en España desde el Renacimiento, pese a los dos grandes intentos que en tal sentido se han hecho en los tres últimos siglos [XVIII, $\mathrm{XIX}, \mathrm{XX}]$, y por tanto una emigración en el cuerpo débil de la ciencia española, todavía inmaduro, ha significado un retroceso mas notable y grave que en otras disciplinas mas arraigadas».

Y luego agrega que la necesidad de una valoración crítica no puede ser trivializada ni reducida «a una conveniencia personal o a una falta de patriotis-

48 Creado en 1907 siguiendo el modelo del Instituto de Francia y sus cinco academias. Los Arxius del Institut de Ciènces fueron concebidos como órgano divulgativo a Sección de Ciencias, dedicada a la investigación de las ciencias matemáticas, físico-químicas y biológicas; en 1923 la revista cambio el nombre por Axius de la Secció de Ciències. Consultado en http://www.iec. cat/gc/ViewPage.action?siteNodeId=926\&languageId=1\&contentId=3065 (08-04-2010).

49 El nombre de Augusto Pi Suñer aparece reiteradamente en la historiografía sobre los debates de esos años en relación las distintas variantes del catalanismo político; la actividad de Pi Suñer se registra como miembro activo el núcleo federal del Ampurdán, provincia de Girona. Consultado en http://www.partitrepublicacatala.cat.htm.

50 García Camarero, E y García Camarero, E (comps.) (1970), La polémica de la ciencia española, Madrid, Alianza. Ernesto García Camarero retoma algunos de los temas del Estudio Introductorio de 1970 en la conferencia; La polémica de la «ciencia española»: ¿una cuestión pendiente?, dictada en 2003 en los Cursos de verano de El Escorial; las comillas dentro del título algo quieren indicar. Consultado en http://elgranerocomun.net (08-04-2010).

51 García Camarero, E. (1978), La ciencia española en el exilio. En Abellán, J.L. (dir.) (1976-1978), El exilio español de 1939, Madrid, Taurus, t. V, pp. 189-243. 
mo». En la relación de médicos exiliados García Camarero incluye a «los científicos de mayor relevancia desde el punto de vista de la investigación y la docencia», pero también otros nombres que «han llegado a nuestras manos, aunque a veces su actividad científica haya sido modesta, pero que por sus estudios y preparación forman un importante grupo de profesionales» ${ }^{52}$.

Si recurrimos al Diccionario Histórico de la Ciencia Moderna en España; en él solo aparecen dos científicos exiliados a Venezuela: el geólogo José Royo Gómez - quien se incorporó a la Universidad Central de Venezuela en 1951 procedente de Colombia- y el fisiólogo Augusto Pi Suñer ${ }^{53}$. Con respecto a Pi Suñer, además de valorar positivamente su papel en la modernización de la fisiología venezolana, en los mismos términos en que lo hacen sus colegas venezolanos ${ }^{54}$, el diccionario enumera y contrasta sus aportaciones en el campo de la fisiología (inmunología, reflejos nerviosos de adaptación y reguladores de la glucemia, bioquímica de los hidratos de carbono, el metabolismo hepático, fisiología renal), para luego señalar:

«el interés por campos tan diversos le restó, tal vez, profundidad en sus investigaciones, pero le permitió, en cambio, la redacción de trabajos síntesis muy bien documentados, e incluso la confección de manuales que obtuvieron un extraordinario éxito»,

para concluir, y ello resulta relevante para su labor en Venezuela:

52 García Camarero (1978), pp.191-192. Las listas del exilio siempre son en general incompletas e inexactas; Giral incluye en Venezuela a: Pi Suñer, Carrasco Forminguera, Boffil Deulofeu, Vicente Martín, Ortega Durán, Mateo Alonso, Bengoa Lecanda, Sahagún Torres, Ruesta Marco, Jaso-Roldán, Sánchez Covisa, Peyrí Rocamora y Pardo Gayoso, mientras que en la de García Camarero solo aparecen: Pi Suñer, Carrasco Forminguera, Sánchez Covisa y Cortés Lladó. Con las prevenciones del caso y la ayuda de un amplio grupo de fuentes avanzamos una lista de los médicos españoles exiliados en Venezuela en MARTín FrechiLLA (2002), pp. 247-250; también en MARTín FrECHILla (2006), pp. 326-350 y pp. 430-444. Sin embargo, Guerra, F. (2003), La medicina en el exilio republicano, Alcalá de Henares, Universidad de Alcalá, en el capítulo dedicado a Venezuela (pp. 717-751), incluye menos médicos exiliados que los del anexo de nuestro artículo. Las valoraciones e inexactitudes de la literatura sobre el exilio se repiten y tiene consecuencias, como las que muestra el reciente artículo Tinao MARTín-PeÑA, J.F. (2005), Los médicos del exilio republicano en Venezuela, Historia Actual On Line, 7, pp. 43-54.

53 LóPez Piñero, J.M. et al. (eds) (1983), Diccionario Histórico de la Ciencia Moderna en España, Barcelona, Ediciones Península, vol. 2, pp. 171-174 y pp. 267-268.

54 De Venanzi, F. (1950), Augusto Pi Suñer, Acta Científica Venezolana, 1 (2), pp. 45 46; GRANIER-DOYEUX (1962). 
«La figura de Pi i Sunyer queda, sin embargo, incompleta si se limita únicamente a su actividad científica. (...). Su capacidad de organización, aglutinación y hasta entusiasmo la puso al servicio de dos ideales: que su país pudiera incorporar los hábitos europeos de investigación de laboratorio y que el idioma catalán se convirtiera en medio normal de comunicación científica» ${ }^{55}$.

De los dos ideales, Pi Suñer pudo desarrollar a plenitud en el país de acogida el primero, con similar capacidad de organización, aglutinación y entusiasmo, con el que lo hizo en el suyo ${ }^{56}$.

En junio de 1939 llegó exiliado a Venezuela. Dejaba atrás una universidad que comenzaría a sufrir la depuración franquista, para exaltar la moral y el dogma católicos, la hispanidad, la autoridad y la jerarquía; una universidad contraria a la que a partir de 1931, con la Segunda República, había empujado de nuevo la autonomía ${ }^{57}$. Encontraría aquí una universidad que comenzaba a desperezarse de forma desigual en los distintos campos disciplinares; en buena parte, porque ante la lenta disolución de la modorra universitaria, la administración pública —obras públicas, salud, agricultura, fomento, hacienda, minas e hidrocarburos, ...- no esperó y comenzó a crear en su seno grupos de docencia para la formación de cuadros y laboratorios e institutos de investigación aplicada ${ }^{58}$.

Dentro de este propicio caldo de cultivo, Augusto Pi Suñer expuso, en la inauguración en junio de 1940 del Instituto de Medicina Experimental (IME), un apretado resumen que ayuda a dar forma, a reunir las piezas que podían faltar en el equipaje que hemos ido llenando. Su discurso recogió, tanto lo esencial de su ideario de investigador científico como el corpus de su doctrina. Del «ideario» destacó: «la medicina va acercándose a la ciencia a medida que se extienden y fortifican sus fundamentos», sin ellos la medicina es empirismo o negocio; la ciencia desinteresada no solo despierta el interés por «los problemas que permiten aplicación práctica inmediata»; tanto o más útil será saber las condiciones de un parásito para vivir o «las maneras de reaccionar el organismo animal, el organismo

55 LÓPEZ PiÑERo (1983), pp. 171-174.

56 En Venezuela también se ocupó de la proyección y defensa del català desde el centro catalán que fundó y presidió en 1945, allí organizaría en 1953 los primeros Juegos Florales de la Lengua Catalana.

57 Charle, Ch. y Veger, J. (1994), Histoire des universités, Paris, PUF, pp. 113-115.

58 Martín Frechilla, J.J. y TeXera Arnal, Y. (comp.) (1999), Modelos para desarmar. Instituciones y disciplinas para una historia de la ciencia y la técnica en Venezuela, Caracas, Consejo de Desarrollo Científico y Humanístico-UCV. 
humano, ante su presencia», como el conocimiento del «parásito fautor de enfermedad»; la labor pedagógica junto al trabajo de investigación es la forma de interesar, de despertar vocaciones para romper la inercia y contagiar entusiasmo. Del corpus de su doctrina enumeró: «el estudio de la sensibilidad interna general, la sensibilidad respiratoria, la sensibilidad atrófica, los procesos de unificación de funciones fijadoras hepática, las de secreción renal, el metabolismo intermediario de los glúcidos, los procesos anaeróbicos en el recambio nutritivo, etc., etc.», todo ello servirá para despertar el interés y la formulación de programas de investigación. Después de un sentido reconocimiento a los veinte años de labor colectiva del Instituto de Fisiología de Barcelona, Pi Suñer retomó el «ideario»:

«Los temas que quedan indicados como objeto de posibles investigaciones son estrictamente científicos. Pero un Instituto de estudios biológicos no puede desatenderse de la realidad vital de la masa social en que se asienta. Las condiciones en que se desenvuelve la vida de los ciudadanos, (...) Problemas como el de la alimentación colectiva, del tono metabólico, de las posibilidades y hábitos nutritivos, etc., para no citar más que unos ejemplos, han de ser motivo de trabajos que reporten resultados prácticos tangibles ${ }^{59} \gg$.

\section{RESONANCIAS}

\section{Primeras iniciativas}

Además de la organización del IME, acordar un programa para sus actividades e ir ajustando la génesis de los trabajos, Augusto Pi Suñer comenzó a establecer los contactos - y lo logró- para obtener una beca rotativa de la Fundación Rockefeller con la cual se pudiese «enviar al exterior a jóvenes que tuvieran interés en las ciencias fisiológicas». Marcel Granier-Doyeux fue a la Universidad de Yale a estudiar Farmacología; «el segundo becario fui yo - dice Francisco De Venanzi-, fui a estudiar Fisiología especialmente aplicada a la nutrición y a la endocrinología» en Yale y Cornell ${ }^{60}$. La experiencia

59 A modo de editorial se reproducen, en Acta Cientifica Venezolana, 17 (2), 1966, pp. 35-37, partes del discurso inaugural de Augusto Pi Suñer, publicado en el diario El Universal de Caracas los días 9 y 11 de junio de 1940.

60 Antillano, P. (1988), Entrevista con Francisco De Venanzi (1983), Boletín del Archivo Histórico de la UCV, 7 (1), pp. 245-310; los dos tomos de este número corresponden al Homenaje a De Venanzi en el I Aniversario de su muerte. 
de Pi Suñer en el campo nutricional y metabólico fue la que enrumbaría a De Venanzi como investigador de la Fisiología de la nutrición, preocupado como estaba por el problema de alimentación de los trabajadores venezolanos; sobre los inicios diría De Venanzi años después en la misma entrevista: «los muchachos que tenían intereses científicos relacionados con las Ciencias Naturales se inclinaban por estudiar Medicina».

La segunda iniciativa de Pi Suñer fue la creación en 1942 de los Anales del Instituto de Medicina Experimental ${ }^{61}$ que publicaron -a diferencia de los Arxius - los resultados de las investigaciones de los miembros del instituto. Pi Suñer publicó 8 trabajos de un total de 27, en los tres volúmenes de la revista; la mitad corresponde a artículos de revisión con bibliografía al día hasta 1939, mientras que en los otros encabeza un equipo compuesto por estudiantes de los últimos años de medicina. Este equipo lo comparte Pi Suñer con De Venanzi y García Arocha para las investigaciones que estos desarrollan bajo su respectiva responsabilidad. En los Anales encontramos en forma de artículo los trabajos que los asistentes de investigación presentaron para obtener el titulo de Doctor en Ciencias Médicas. Juan Bautista Boffil, médico catalán exiliado, graduado en Madrid en 1930 y asistente de Pi Suñer en Barcelona, publicó un artículo con la colaboración de uno de los asistentes; la escasa y contradictoria información sobre Boffil impide asegurar si el trabajo publicado fue realizado en el IME o, por el contrario, lo fue en el laboratorio privado de farmacología que había fundado en 1942 con otros dos médicos catalanes: José Isern y Buenaventura Benaiges ${ }^{62}$.

Es evidente que el Instituto siguió desde el inicio las pautas de un programa de investigación científica: formación y especialización de sus investigadores, organización de equipos y proyectos, estabilidad del personal auxiliar y creación de un órgano propio para la publicación de los resultados de investigación; revista que, por otra parte, pudiese ser intercambiada con otras revistas especializadas del exterior, dentro de un programa para la adquisición de bibliografía y de los equipos y materiales necesarios ${ }^{63}$.

61 El segundo volumen correspondió al período 1943-1944 y el tercero — y último- a 1945-1946; aunque no se han encontrado razones para la interrupción de los Anales, es posible que los acontecimientos políticos que implicaron - como veremos - la baja temporal de Humberto García Arocha hayan afectado temporalmente la productividad del instituto.

62 Martín Frechilla (2006), p. 442.

63 La historia del Instituto de Medicina Experimental es una asignatura pendiente en la historiografía venezolana sobre las instituciones científicas. 
Biológicas o Naturales

La Academia de Ciencias Físicas, Matemáticas y Naturales de Venezuela la creó el Congreso Nacional en 1917, pero no sería hasta 1933, cuando el Ejecutivo designó los individuos de número. Por otra parte, la Sociedad Venezolana de Ciencias Naturales (SVCN) fue creada en 1931; en ella destacaban, al momento de su fundación, médicos inclinados hacia la salud pública y médicos orientados hacia la biología, en especial a la botánica, con algún naturista y geólogo. Entre estas corrientes hay que buscar el cruce de tensiones en torno a la institucionalización de la docencia y la investigación en Ciencias Naturales en la Universidad Central de Venezuela. Contencioso que muestra: por un lado, a Augusto Pi Suñer y Francisco De Venanzi y, por el otro, a Tobías Lasser (1911-2006), graduado de médico en la UCV en 1938 - no de Doctor Ciencias Médicas - , confirmando la citada referencia de De Venanzi de que quienes estaban interesados en la investigación científica en esos años no tenían otra opción sino estudiar Medicina para poder iniciarla.

Tobías Lasser, quien estudió una maestría en ciencias en la Universidad de Michigan ${ }^{64}$, regresó en 1941 convertido en botánico. En 1945 fundó, en la Universidad Central de Venezuela, el Jardín Botánico apoyado por la SVCN y, en especial, por su maestro Henri Pittier (1857-1950) quien desde 1919 había catalogado el Herbario Nacional ${ }^{65}$. Ésta fue primera iniciativa universitaria de Lasser para luego promover, en 1946, la creación de un Instituto de Ciencias Naturales desde la Academia de Ciencias Físicas, Matemáticas y Naturales, de la cual era entonces Secretario: Lasser «fue quien concibió la idea y le dio el impulso necesario para que se pudiera llevar a cabo» ${ }^{66}$. De Venanzi, por su parte, había sido nombrado, en 1945 al regresar del postgrado, Jefe de Trabajos Prácticos del IME y poco después asumiría un cargo de mayor responsabilidad académica como Secretario del instituto. Con la presentación de estos dramatis personae, solo queda situar el contexto académico y político dentro del cual se inserta la proposición de Lasser de crear un

64 Pocas dudas puede haber aún hoy sobre el prestigio académico de las universidades de Michigan (pública), Yale y Cornell (privadas) en las que estudiaron Lasser y De Venanzi.

65 Ingeniero, botánico y naturalista nacido en Suiza, llegó por primera vez a Venezuela en 1913 contratado por el gobierno para asesorar en la creación de una escuela de agricultura; desde 1919 desarrolló nuevas iniciativas como botánico, conservacionista, fitogeógrafo y educador. TeXera Arnal, Y. (2006), Henry Pittier y los inicios del Herbario Nacional de Venezuela, Acta Botánica Venezuelica, 29 (2), pp. 369-383.

66 Castillo De Gurfinkel, L. (1995), La enseñanza de la Ciencias Naturales y la generación del 46, Caracas, Universidad Pedagógica Experimental, p. 502. 
Instituto de Ciencias Naturales y la sintonía entre Pi Suñer y De Venanzi para oponerse a ello fuera del ámbito y control de las ciencias médicas.

El 18 de octubre de 1945 un golpe de estado reunió a jóvenes militares resueltos a liquidar los vestigios del pasado gomecista, junto a civiles del partido socialdemócrata - Acción Democrática - impacientes por acortar el camino al poder. Faltaban apenas unos meses para que finalizara el período de gobierno y el signo político del golpe fue inicialmente confuso. El gobierno de Isaías Medina Angarita estableció relaciones diplomáticas con la Unión Soviética, además de haberse aliado con los comunistas para ganar las elecciones municipales a comienzos de 1945. Entre los exiliados de la Guerra Civil española hubo diversas reacciones por la incertidumbre de lo que podía depararles un gobierno cívico-militar ${ }^{67}$; algunos, como los hermanos Trueba, salieron a defender el régimen depuesto ${ }^{68}$. La confusión fue tal, que dos miembros de la Junta de Amigos de los Republicanos Españoles — uno del partido de gobierno (Partido Democrático Venezolano) y otro de la oposición (Acción Democrática)-, condenaron el golpe de estado desde México, en donde se encontraban para rendir homenaje y saludar al gobierno reconstituido de la Segunda República española en el exilio. La Junta Revolucionaria de Gobierno fue tajante con respecto al porvenir en la cárcel de los hermanos Trueba; siguió el mismo consejo que Nelson Rockefeller le había dado, en abril de 1945, a la Junta Española de Liberación: «rehuyan en lo sucesivo todo contacto político con el Partido Comunista ${ }^{69}$. El 8 de noviembre de 1945 Venezuela reconoció al gobierno de la Segunda Republica Española en el exilio; las relaciones diplomáticas con el gobierno de Franco quedaron de hecho rotas al no solicitar el venezolano que éste lo reconociese, si bien oficiosamente nunca se interrumpieron.

67 Si bien desde 1936, los dos gobiernos de la transición democrática estuvieron encabezados por Eleazar López Contreras e Isaías Medina Angarita, ambos militares, ellos fueron elegidos por el Congreso Nacional, renovado electoralmente.

68 El caso más significativo fue el protagonizado por los hermanos Trueba, comunistas catalanes, que asumieron una actitud beligerante ante el nuevo gobierno y fueron encarcelados. El exilio republicano en Venezuela, y las fuerzas políticas que lo componían - anarquistas, socialistas, comunistas, nacionalistas...- quedaron seriamente marcadas por los sucesos de este golpe de estado y los del que dieron los militares en noviembre de 1948 para deshacerse de sus socios civiles. MARTín FreChiLla, J.J. (1997a), Tensiones del exilio español en Venezuela: El caso de los hermanos Trueba, Cuadernos Republicanos, 30, pp. 75-90.

69 Martín Frechilla, J.J. (1997b), Confianza, desazón y malestar. Las relaciones de Venezuela con las dos Españas: 1936-1949, Paramillo, 16, pp. 215-320; cita tomada de DEL VALLE, J.M. (1976), Las instituciones de la república española en exilio, Paris, Ruedo Ibérico, pp. 103-104. 
A los pocos días del golpe, un manifiesto del profesorado de la UCV mostró un amplio panorama de adhesiones. De Venanzi, Granier-Doyeux y García Arocha firmaron junto a 115 profesores de los 165 que constituían entonces el cuerpo académico. Humberto García Arocha fue nombrado Ministro de Educación Nacional. Pasado el susto inicial, el exilio republicano se sintió confortable, con la excepción política señalada. La nueva sintonía potenció el papel que la Dirección de Cultura Universitaria de la UCV estaba cumpliendo desde 1944 al ampliar y diversificar los Cursos Libres y los Ciclos de Conferencias. Cursos y conferencias impulsados entre otros por Pi Suñer, consciente éste de la necesidad social de una extensión universitaria similar a la impulsada por Altamira en la Universidad de Oviedo; en estas actividades participaron de un modo destacado los exiliados. Ésta Dirección operó en la práctica como modesta réplica de la Casa de España en México ${ }^{70}$, ante las tensiones político-partidistas del exilio en la homóloga venezolana. Así, a los exiliados residentes en el país que Pi Suñer incorporó a los cursos, se sumaron otros que dictaron cursos por períodos más o menos largos ${ }^{71}$. Por otra parte, la nueva situación política también trajo la promulgación, en octubre de 1946, de un Estatuto Orgánico de la Universidades Nacionales con el objeto de vigorizarlas dentro de un marco - aún restringido - de autonomía académica: la universidad venezolana «debe establecer dependencias destinadas a la investigación científica (...) investigación pura destinada a ampliar cada vez más nuestro horizonte científico e investigación aplicada, orientada a obtener el conocimiento preciso y la solución adecuada de problemas, especialmente de los nacionales» $\rangle^{72}$.

Desde el Ministerio de Educación Nacional, García Arocha presionó al Consejo Universitario de la UCV para que acelerase el proyecto - en marcha antes del golpe de estado - de crear una Facultad de Filosofía y Letras (FFL) que debía plantearse «un intercambio a base de profesores extranjeros calificados que puedan iniciar su trabajo cuanto antes». A finales de 1946 el Rector le comunicaba al ministro el entusiasmo con el que «ha sido acogida la fun-

70 Lida, C., Matesanz, J.A. y MorÁn, B. (1989), Las instituciones mexicanas y los intelectuales españoles refugiados: la Casa de España en México y los Colegios del Exilio. En ABELlan, J.L. y MonClús, A. (coords.) (1989), El pensamiento español contemporáneo y la idea de América. II. El pensamiento en el exilio, Barcelona, Editorial Anthropos, pp. 79-155.

71 Entre otros lo hicieron Marcelino Pascua Martínez, Luís Jiménez de Asúa, Pedro Pi Calleja, Fernando de los Rios y José Giral; estos últimos recibieron, además, nuestro doctorado Honoris Causa, al igual que Pi Suñer, en 1947. MARTín FreChILla (2006), pp. 357-358 y p. 367.

72 ACUUCV, CU 291947. 
dación y la numerosa matrícula de estudiantes que sobrepasó todos nuestros cálculos iniciales» ${ }^{73}$. En el pensum de estudios se incluyeron, como componente obligatorio, tres cursos de ampliación cultural y científica, uno de ellos de «biología y fisiología del sistema nervioso». Tobías Lasser aprovechó éste último componente, propuso la creación de un Departamento de Ciencias Naturales adscrito a la nueva Facultad y se hizo cargo de el.

Pero no se encontraba confortable el Departamento anexo a la FFL, tanto por la inserción temática como por las particulares necesidades de espacio y equipamiento que requerían los cursos que Lasser comenzó a impartir «con el objeto de familiarizar a los alumnos que así lo deseen con los métodos de la investigación científica» ${ }^{74}$. El Departamento, y la rápida pretensión de Lasser de convertirlo en Instituto y Escuela de Ciencias Naturales, trajo tensiones y resistencias. El Decano de la FFL decidió debatir el tema casi de inmediato. Solicitó, a Augusto Pi Suñer y a Humberto García Arocha una opinión sobre el proyecto presentado por Tobías Lasser. Proyecto que incluía, además de la argumentación sobre la enseñanza de las Ciencias Naturales: una estructura apoyada en el Estatuto Orgánico, relativa a la docencia y a la investigación; la creación de una Escuela - que otorgaría el titulo de licenciado- compuesta por cuatro Departamentos - Biología, Geología, Física y Química-; y el plan para la investigación en un Instituto de Ciencias Naturales. Pi Suñer no quiso afrontar en solitario la tarea, estando García Arocha en el ministerio, y resolvió convocar a un grupo de «científicos todos de indiscutible autoridad y competencia en el campo de las Ciencias Biológicas» ${ }^{75}$.

73 Domingo Casanovas - filósofo exiliado y profesor en la Facultad de Derecho- jugó un papel esencial en el proyecto como miembro de la Comisión Organizadora de la nueva Facultad; los primeros exiliados contratados en el exterior fueron, en septiembre y octubre de 1946, los filósofos Eugenio Imaz y Juan David García Bacca. Sobre la creación de la Facultad de Filosofía y Letras, el papel de los profesores exiliados y cómo estos fueron afectados por los acontecimientos políticos y universitarios del golpe de estado de 1948 y la intervención de la universidad en 1952 véase: MARTín FRECHILLA (2006), pp. 483-507.

74 ACUUCV, CU 21 A Oficios 1946.

75 Henry Pittier, Enrique G. Vogelsang, médico veterinario y decano de la Escuela de Medicina Veterinaria —en la cual Pi Suñer estaba contratado desde 1944 para la Cátedra de Bioquímica-, Francisco De Venanzi, Jefe del Departamento de Investigación del Instituto de Medicina Experimental, Víctor M. López, geólogo de la Escuela de Ingeniería, Francisco Tamayo, profesor de Ciencias Biológicas del Instituto Pedagógico y dos médicos más Alberto Rivero y Félix Pifano, responsable este último de la Cátedra de Patología tropical, quien llevaba varios años batallando para que su cátedra se convirtiera en Instituto de Medicina Tropical y así trasladar el grupo de investigación consolidado en el Instituto Nacional de Higiene junto a Martin Mayer. 
A la Opinión acerca de la enseñanza de las Ciencias Naturales en la Facultad de Filosofia de la Universidad Central no se sumaron Tamayo, Pifano, Rivero y López; todos expusieron por escrito sus razones: una mezcla de intereses académicos junto a posicionamientos doctrinales sobre la hegemonía de las ciencias médicas en el territorio de las naturales. Los cuatro destacaron a Lasser como un novel investigador bien preparado y entusiasta, capaz de llevar adelante el proyecto. Pi Suñer, García Arocha, Pittier, Volgelsang y De Venanzi, se opusieron:

«mal puede denominarse Instituto de Ciencias Naturales a un organismo que carece de laboratorios, que no dispone de espacio, ni de locales, ni de dotación con que emprender la actividad esencial de un centro de esta índole, que es la investigación científica; que carece de profesores en número y calidad suficiente como para realizar una labor metodizada y de proyecciones nacionales; que carece de bibliotecas y museos, que no ha planificado previamente el trabajo a realizar en el campo de las Ciencias Naturales en Venezuela, donde las investigaciones de orden botánico y zoológico requieren una institución universitaria lo suficientemente organizada que emprenda un trabajo sistemático y amplio, en relación con nuestra flora y nuestra fauna, donde colaboren el investigador capacitado para el estudio de los fenómenos dinámicos, el bioquímico, el morfologista y el personal auxiliar requerido por las técnicas e investigaciones especializadas.

Creemos además que la fundación de un Instituto de Ciencias Naturales es una obra seria, que necesita estudio detenido y suficiente por el que, mediante la concurrencia de diferentes opiniones autorizadas, puede elaborarse un plan orgánico que garantice la adecuada orientación y satisfaga los requerimientos académicos, cuyas exigencias y buen crédito deben estar salvaguardados desde el principio contra los irremediables defectos que acarrearía la improvisación y la falta de análisis frente a los variados problemas que plantea su fundación y organización ${ }^{76}{ }_{\Downarrow}$.

No había sido ésta la situación que encontró Pi Suñer en 1939. La Opinión proponía crear una Facultad de Ciencias Biológicas cercana, no solo físicamente, a las facultades de Ingeniería Agronómica y de Medicina Veterinaria ${ }^{77}$. Sobre los cursos de Biología que dictaba Lasser, apuntaban que debían ser dictados por científicos con «amplia experiencia y un profundo conocimiento (...) [y que] posean al propio tiempo una adecuada visión acerca del alcance, sentido y cabal significación que imprimirán estas disciplinas complementarias».

76 ACUUCV, CU 28 1947. Se trata de un expediente completo con la correspondencia y las opiniones.

77 Ambas facultades de la Universidad Central de Venezuela están situadas en la ciudad de Maracay a 100 kilómetros de Caracas. 
Se enfrentaban dos modelos con respecto a las ciencias biológicas, dentro del ámbito de investigación de las ciencias médicas o fuera de este ${ }^{78}$. En enero de 1947, el rector le comunicó a Tobías Lasser que el Departamento de Ciencias quedaba adscrito directamente al rectorado como Departamento Autónomo $^{79}$. En junio de 1947, estaban listos proyecto y reglamento para una Escuela de Ciencias Naturales adscrita a la Facultad de Ciencias Físicas y Matemáticas; el departamento de Biología fue el que otorgó las primeras licenciaturas. En 1951 Lasser insistió en el tema en unas «Consideraciones sobre la creación de una Facultad de Ciencias en la Universidad Central» ${ }^{80}$ y, por otra parte, creó Acta Biológica Venezuelica como «órgano de la sección de Biología de la Facultad de Ciencias Matemáticas y Naturales» ${ }^{81}$.

Con todos los términos del debate académico y la inserción sobre la mesa en la Ley de Universidades Nacionales aprobada en julio de 1953 —en plena dictadura de Marcos Pérez Jiménez-, se identificaba a «Ciencias» como una de las facultades universitarias. Antes de la promulgación de la ley - muestra evidente que De Venanzi había estado detrás de ella - un editorial de Acta Científica Venezolana - revista de la Asociación Venezolana para el Avance de la Ciencia desde 1950 - señalaba como aspectos positivos de la ley: que reconocía «la necesidad urgente del desarrollo de las ciencias básicas, considerando así la física y matemáticas, la química y la biología»; el editorial abogaba por la concentración de su enseñanza con Institutos de Física, Química y Biología, como «núcleos fundamentales de la Facultad de Ciencias» ${ }^{82}$. Con la ley de 1953 la Escuela de Ciencias siguió adscrita a la ahora denominada Facultad de Ingeniería; en 1958, con De Venanzi de rector de la UCV, fue creada la Facultad de Ciencias, inicialmente con las Escuelas de Biología, Física y Química.

78 TeXera Arnal, Y. (2007), Government and University: The Emergence of Academic Biology in Venezuela, Science, Technology \& Society, 12 (1), pp. 11-26.

79 Lasser nombró una Junta Consultiva para el Departamento de Ciencias Naturales con Víctor M. López y Alberto Rivero, junto a Guillermo Zuloaga (1904-1984) ingeniero geólogo de la Escuela de Geología de la UCV; Walter Dupouy (1906-1978) autodidacta destacado en antropología, espeleología y geología y Wiliam H. Phelps (1902-1988) naturalista. Diccionario de Historia de Venezuela (1997), vol.4, p. 355; vol. 2, p. 147; vol. 3, p. 624.

80 LASSER, T. (1951), Consideraciones sobre la creación de una Facultad de Ciencias en la Universidad Central, Acta Científica Venezolana, 2 (3), pp. 134-135.

81 La Facultad de Ciencias Matemáticas y Naturales constituye un cambio de denominación de la Facultad de Ciencias Físicas y Matemáticas entre la derogación del Estatuto de 1946 y la Ley de Universidades de 1953.

82 S.F. (1953), Editorial, Acta Cientifica Venezolana, 4 (3), p. 83. 
Avance de la ciencia

El golpe de estado de noviembre de 1948 contra el presidente Rómulo Gallegos no cogió a nadie por sorpresa y pocos salieron a oponerse. Quienes lo justifican resaltan las tensiones desatadas por Acción Democrática al disponer de mayoría absoluta y hacer un uso sectario de ella. El exilio republicano vio con preocupación la nueva situación, y más cuando las relaciones oficiosas de Venezuela con Franco tomaron rápidamente el rumbo de hacerse oficiales. Pero la Cancillería venezolana solicitó reunirse con un grupo representativo de los exiliados. Pi Suñer fue, junto con el cónsul republicano, uno de los cuatro que asistieron. Una vez que escucharon las garantías de que los exiliados no tenían nada que temer, Pi Suñer aprovecho para solicitar que la representación republicana pudiese actuar oficiosamente a fin de seguir documentando a los exiliados españoles. Y así ocurrió.

Julio de Armas (1908-1990) fue designado rector de la UCV en 194883; al asumir el cargo expresó la aspiración de que los componentes autonómicos del Estatuto universitario tuviesen rango de ley. De Armas fue rector hasta junio de $1951^{84}$. Con la destitución del rector comenzaron a entrar en escena claros signos de autoritarismo; en octubre de 1951 era derogado el Estatuto y se decretaba para al UCV un Consejo de Reforma. De inmediato 267 profesores universitarios firmaron una carta para exigir la derogatoria del Decreto y la restitución del Estatuto: «estamos decididos a separarnos de los cargos docentes y de investigación que venimos desempeñando en el caso de que no se llegue una solución satisfactoria que deje incólume la autonomía universitaria» ${ }^{85}$.

Francisco De Venanzi fue uno de los que mantuvieron la palabra ${ }^{86}$. Para ese momento la Asociación Venezolana para el Avance de la Ciencia (Aso-

83 Médico graduado en la UCV en 1932, además de profesor universitario, político, escritor y diplomático. VVAA., La UCV en el tiempo de Julio de Armas (1948-1951), Boletín del Archivo Histórico de la UCV, 9, pp. 11-23.

84 Para ese momento, los cambios y las tensiones políticas no era menores: Carlos Delgado Chalbaud, presidente de la Junta Militar, había sido asesinado el 13 de noviembre de 1950.

85 Rivas Rivas, J. (1977), Historia Gráfica de Venezuela. 4. La Junta Militar y la Junta de Gobierno. Noviembre 1958-Diciembre 1952, Caracas, Centro Editor, pp. 163-164.

${ }^{86}$ Con el mecenazgo de su padre, el médico Marcel Roche y Francisco De Venanzi crearon un Instituto de Investigaciones Médicas, que en 1959 se reconvertiría - al unirse con el Instituto Venezolano de Neurología e Investigaciones Cerebrales fundado en 1955 por Humberto Fernández Morán - en el Instituto Venezolano de Investigaciones Científicas (IVIC), ambos dependientes de la administración pública pero separados del ámbito universitario. Marcel Roche fue el primer Director del IVIC, y luego del Consejo Nacional de Investigaciones Científicas y Tecnológicas (CONICIT). 
VAC), fundada en 1950, había celebrado en Caracas su primera Convención anual y la revista Acta Científica Venezolana estaba en circulación ${ }^{87}$. En 1949, De Venanzi había convocado en los locales del IME a un grupo inicial $^{88}$ para promover la creación de la asociación ${ }^{89}$. El accidente vascular cerebral no permitió a Pi Suñer asistir a una convocatoria cuyo interés sin duda había compartido con De Venanzi ${ }^{90}$. Que el mexicano Jaime Torres Bodet fuese designado en julio de 1948 director general de la UNESCO aceleró las iniciativas emprendidas por De Venanzi, quien con respecto a la constitución de AsoVAC diría años después: «el silencio científico del país era impresionante y preocupado por la ausencia de un clima positivo para el desarrollo de la investigación propuse a algunos compañeros y amigos la formación de un organismo del tipo de las asociaciones para el progreso de la ciencia que existían ya en varios países» ${ }^{91}$. A pesar de las tensiones que el ambiente político

87 Martín Frechilla, J.J., Texera Arnal, Y. y Cilento Sarli, A. (2005), Un archivo para la historia: Acta cientifica Venezolana 1950-2000, Caracas, Consejo de Desarrollo Científico y Humanístico-UCV. El libro incluye un CD con todos los sumarios de la revista, así como, escaneados, los editoriales y los artículos de Pi Suñer, De Venanzi, Houssay y otros; en el portal http://fau.ucv.ve/infodoc/ de nuestra Unidad de Documentación es posible consultar en línea en el archivo Acta esa documentación.

88 Ellos fueron: Vicente Peña (Doctor en Ciencias Médicas UCV 1902), Werner G. Jaffe (nacido en Alemania, doctorado en Químíca en Zurich, llegó a Venezuela en 1940, responsable de la cátedra de Bioquímica de la Facultad de Ciencias Médicas de la UCV y Jefe de Investigación del Instituto Nacional de Nutrición del MSAS), Herman Kaiser (nacido en Alemania, doctorado en Química en Freiburg, llegó a Venezuela en 1938, profesor de Química en la Facultad de Ciencias Físicas y Matemáticas de la UCV) y Oscar Agüero (Doctor en Ciencias Médicas UCV 1941).

89 Como posible antecedente, existe una muy precaria información acerca de una Asociación de Científicos en Venezuela de la que solo disponemos una carta dirigida, el 29 de noviembre de 1949, al Centro de Cooperación Científica para América Latina de la UNESCO en Montevideo; la carta anexa una lista de los «científicos más importantes de Venezuela» (29) entre los que no se encuentran De Venanzi o Pi Suñer, tampoco Peña, Jaffe, Kaiser y Agüero, pero si lo están Felix Pifano, Guillermo Zuloaga, Victor M. López y Tobías Lasser; ¿casualidad? Archivo del Jardín Botánico de la UCV, P 187 (localizado por Yolanda Texera Arnal). La pesquisa sigue abierta, porque podría ayudar a precisar otras razones en la gestación de AsoVAC, sobre todo cuando la primera reunión convocada por De Venanzi es contemporánea con la carta enviada a Montevideo por la Asociación de Científicos en Venezuela.

90 A la firma del Acta Constitutiva -20 de marzo de 1950- asistió Pi Suñer, quien había sido nombrado Miembro de Honor; entre los 63 fundadores se encontraban dos exiliados más: José María Bengoa (nutricionista) y José M. Cruxent (arqueólogo).

91 De Venanzi, F. (1970), ¿Es necesaria la ciencia?, Acta Cientifica Venezolana, 21 (1), pp. 129. 
ofrecía, la atmósfera del ámbito científico permitió que la AsoVAC y Acta pudieran comenzar su travesía sin mayores contratiempos y avanzar como asociación privada. El apoyo de la UNESCO se vio reforzado por la visita de Torbjorn Caspersson - Director del Instituto de Citología del Instituto Carolíneo de Estocolmo y Consejero del Centro de Cooperación Científica para la América Latina de la UNESCO - quien luego de evaluar la situación propuso la organización de un «Consejo Venezolano de Investigación Científica» dentro de la administración pública orientado al estímulo y coordinación de proyectos científicos individuales, la facilitación para reclutar y seleccionar personal científico competente, $\mathrm{y}$, finalmente, la organización de institutos de investigación ${ }^{92}$.

Las Convenciones anuales de AsoVAC y la regularidad de Acta - trimestral- despertaron el interés de la comunidad científica nacional; allí los veteranos y los jóvenes encontraron la posibilidad de presentar y publicar los resultados de sus investigaciones. Tanto en las convenciones como en la revista se debatieron también - conferencias inaugurales, editoriales, artículos generales o de revisión - asuntos y problemas del momento: sentido social de la ciencia, importancia del avance científico, fe en el poder de la ciencia y en su capacidad de imponer "una racionalidad ética a la política», pensamiento crítico y tolerancia. De Venanzi fue, sin duda, el que impulso la discusión de estos temas. En las Convenciones, los exiliados republicanos comenzaron a presentar regularmente los resultados de sus investigaciones y a participar como responsables de mesas de trabajo de acuerdo a sus áreas temáticas ${ }^{93}$. A las comunicaciones se sumó el destacado papel que AsoVAC otorgó, en las convenciones anuales, a tres exiliados de excepción para que dictasen las conferencias inaugurales: Augusto Pi Suñer «De lo prelógico a lo científico», José María Bengoa «La ciencia para el avance de la Sociedad» y Juan David García Bacca «Implicaciones Filosóficas de Algunas Teorías de Biología Matemática ${ }^{94}$. El canal conductor de Carracido a Pi Suñer y de éste a De Venanzi, fue sin duda una de las claves del exitoso proyecto emprendido por el fisiólogo venezolano.

92 CAspersson, T. (1951), Memorandum sobre la Organización de un Consejo Venezolano de Investigación Científica, Acta Científica Venezolana, 2 (4), pp. 138-143.

93 José María Bengoa, nutrición; José Souto Candeira, neuroquímica y metabolismo; Rosendo Carrasco Forminguera, hematología; Alberto Mateo Alonso y José Solanes Vilapreño, psiquiatría y neurología; José Royo Gómez, ciencias químicas y geológicas; Pablo Vila, geografía; Carlos Díaz Ungría medicina veterinaria y zoología; Juan Sardá, teoría económica; Ángel Palacio Gros, matemática.

94 Los textos de estas conferencias fueron publicados en Acta Cientifica Venezolana. 
Iniciativa universitaria

La proyección de la Junta para Ampliación de Estudios e Investigaciones Científicas en lo relativo al fomento del sector público a la investigación tuvo que esperar en Venezuela hasta 1967. Fue entonces cuando a partir del modelo del informe de Caspersson, y la incorporación parcial de otros proyectos —entre ellos el de AsoVAC impulsado por De Venanzi-, se creó el Consejo Nacional de Investigaciones Científicas y Tecnológicas (CONICIT) ${ }^{95}$. Desde el editorial «El Consejo Nacional de Investigación Científica» de 1951, De Venanzi no había cejado en su empeño de presionar en Acta Científica Venezolana sobre ésta necesidad. A pesar de los casi veinte años de retraso, el papel de De Venanzi a la caída de la dictadura de Pérez Jiménez en 1958, fue determinante para la institucionalización de la ciencia en Venezuela y presionar la creación de un ente publico que la prohijase. De Venanzi presentó desde AsoVAC en 1958 a la Junta de Gobierno un proyecto de Ley para la creación del CONICIT con el argumento de que «la promoción de la investigación científica y del desarrollo tecnológico es vital en la lucha por la independencia económica». Lo hizo al mismo tiempo que preparaba el proyecto de ley de universidades que sería aprobado en diciembre de 1958, mientras estaba encargado de la transición académica de la UCV. Al margen de las negociaciones políticas externas a la universidad para la aprobación de un organismo público de la promoción de la investigación y el desarrollo tecnológico, la ley de universidades dió forma a una universidad en la cual, a partir de las ciencias médicas, se desplegaría el modelo humboldtiano transferido a los estudios de medicina por Flexner en las universidades norteamericanas ${ }^{96}$ : la de Johns Hopkins y, en especial, la de Yale donde De Venanzi había estudiado. Es así como los argumentos del ministro Amalio Jimeno en la exposición de motivos para la creación de la JAE en torno a la modernización de la ciencia en España, a su cultivo desinteresado, a la influencia de la investigación sobre la educación, al acceso al conocimiento allí en donde se encontrase, tuvieron 50 años después una exitosa resonancia entre nosotros ${ }^{97}$, gracias, entre otros,

95 TeXera Arnal, Y. (1983), Ciencia e ideología. Antecedentes de la creación del Conicit venezolano. En DiAz, E., TEXerA, Y. y Vessuri, H. (comps), La ciencia periférica. Ciencia y sociedad en Venezuela, Caracas, Monte Ávila editores, pp. 167-198.

96 GRANDE Covián, F. (1988), Las tres raíces de la Universidad norteamericana, Cuenta y razón del pensamiento actual, 39, pp. 7-12, disponible en http://www.cuentayrazon.org/ (consultado el 08-04-2010).

97 Sobre este tema véase: Dosil MANCILLA, F.J. (2007), La JAE peregrina, Revista de Indias, LXVII (239), pp. 307-332. 
al aporte de Pi Suñer en los debates que tuvo con sus colegas venezolanos en el Instituto de Medicina Experimental.

Pero la primera iniciativa concreta y exitosa por institucionalizar la modernización de la ciencia en Venezuela fue universitaria. Antes de que se aprobase la Ley de Universidades a finales de 1958, la Comisión Universitaria presidida por De Venanzi acordó la creación en la UCV del Consejo de Desarrollo Científico y Humanístico $(\mathrm{CDCH})$, con el objetivo de dar organicidad al fomento de la investigación universitaria, así como, para abrir a los egresados meritorios y a los profesores la posibilidad de cursar estudios de cuarto nivel dentro y fuera del país ${ }^{98}$. $\mathrm{El} \mathrm{CDCH}$ se fundó con cuatro campos de trabajo: concesión de becas para los egresados a fin de formar por esa vía a los futuros profesores e investigadores; concesión de becas de perfeccionamiento y especialización para los profesores; subvenciones para la presentación de trabajos en congresos científicos relevantes a fin de incentivar el mejoramiento y la productividad académica; y subvención directa a proyectos de investigación tanto para la adquisición de materiales y equipos como para la contratación de personal bien sean técnicos nacionales o expertos extranjeros. Al dejar el rectorado en 1963, De Venanzi pudo mostrar en su Mensaje al Claustro $^{99}$ — una memoria y cuenta de excepción-, el maridaje entre universidad y desarrollo, investigación y productividad, al destacar el papel cumplido por el Consejo de Desarrollo Científico y Humanístico bajo la premisa de que la investigación era «una tarea ineludible del profesor universitario»; tarea ésta de múltiples asuntos: desde «las pesquisas más desinteresadas hasta la búsqueda llevada a cabo con propósitos utilitarios inmediatos». Destacaba De Venanzi que el piso conceptual con el cual había operado el CDCH era el de «estimular y ayudar con mayor intensidad» los trabajos de investigación que respondiesen mejor a los propósitos de conjugar «armónicamente la libertad de investigación de los profesores con el interés que pueda existir en los cuerpos directivos por el estudio de determinadas cuestiones».

$$
* * * *
$$

Con la Asociación Venezolana para el Avance de la Ciencia, la revista Acta Científica Venezolana y el Consejo de Desarrollo Científico y Humanístico

98 La Ley de 1958 incluyó la creación de organismos similares en todas las universidades nacionales.

99 De Venanzi, A. (1963), Mensaje al Claustro, Caracas, Ediciones de la Biblioteca de la UCV, reeditado en 1997. 
de la UCV, De Venanzi cerraba, más allá de la fisiología, la primera parte de su ciclo como promotor de la ciencia en Venezuela, aquella que inicio en 1943 al colocar como epígrafe de un trabajo, una cita de Pi Suñer extraída de El hambre de los pueblos ${ }^{100}$. Cita que reúne con claridad la resonancia del equipaje que trajo Pi Suñer a Venezuela, la sintonía entre los dos investigadores y el impulso que De Venanzi desarrolló por propia iniciativa: «Nuestra misión no termina egoístamente en la rebusca fría de los secretos de la vida. Vivimos sumergidos en nuestro mundo y a él nos debemos. Ay! De las clases intelectuales que se muestren indiferentes a los destinos de sus pueblos». En 1962, siendo Francisco De Venanzi rector, Augusto Pi Suñer viajo a México, buscando el cobijo familiar de su hijo antes de morir en 1965.

Fecha de recepción: 23 de marzo de 2008

Fecha de aceptación: 21 de octubre de 2008

100 Anales del Instituto de Medicina Experimental, 3, 1945-1946, p. 14. 